\title{
The quantity, not the quality, of affect predicts memory vividness
}

\author{
DANIEL REISBERG and FRIDERIKE HEUER \\ Reed College, Portland, Oregon \\ and \\ JOHN MCLEAN and MARK O'SHAUGHNESSY \\ New School for Social Research, New York, New York
}

\begin{abstract}
Vivid or detailed memories are reliably associated with the recollection of emotional events. However, the mechanism through which emotionality has this impact remains unspecified. Our results indicate that the character of the emotion does not influence memory vividness; instead, vividness seems to be dependent only on the quantity of emotion that accompanies the event. We consider the implications of this for accounts of emotion's effects.
\end{abstract}

One striking feature of our memories is the degree to which the vividness of memory varies from one event to the next. One may be able to recall some memories with considerable clarity but to recall others (if at all) only sketchily. Why should we care about the vividness (as opposed to the accuracy or accessibility) of a memory? The vividness of a memory typically reflects the presence of a great many details incidental to a memory's informational core. Incidental or not, these details serve important functions: First, the details serve as retrieval cues through which the memory can be accessed. Second, these details may play a pivotal role in determining how we react to a memory. Several authors have recently drawn attention to the fact that "remembering" is not merely a problem of bringing into awareness some forgotten fact or scene; the thought must be understood as bcing a memory, and not regarded as, say, some chance association that happens to have come to mind. If we decide the thought is of the latter sort, we are likely to reject it-not report it, not act on it, and so on. One important cue in this decision seems to be the vividness or completeness of the thought that comes to mind. Put simply, we find some of our thoughts subjectively more compelling than others, and this depends in part on the detailedness of the thought (see Baddeley, 1982b; Johnson, 1985). Intriguingly, there is some suggestion that it is this memory decision, rather than the recovery of the information per se, that is defective in some forms of clinical amnesia (Baddeley, 1982a; Jacoby, 1982; Schacter \& Tulving, 1982).

Several recent studies point to the role of emotion in the creation of vivid memories. This research has largely centered on so-called "flashbulb" memories, such as the

\footnotetext{
We with to express our thanks to Joseph Greenbaum and Peter Monk for their extensive discussion of these issues. Requests for reprints should be sent to D. Reisberg, Psychology Department, Reed College, Portland, OR 97202.
}

memory many of us have of our first learning of John Kennedy's assassination (Brown \& Kulik, 1977; Neisser, 1982; Pillemer, 1984; Rubin \& Kozin, 1984; Winograd \& Killinger, 1983). Brown and Kulik's early descriptions of flashbulb memories pointed to the importance of surprise and the consequentiality of an event in creating these memories. However, the results of subsequent studies have been equivocal on the role played by these factors, and have pointed instead to the importance of emotion: Vivid memories seem most likely for events that evoked strong emotional feelings at the time the events took place (Pillemer, 1984; Rubin \& Kozin, 1984). However, this correlational fact by itself tells us little about mechanism. One possibility is that emotions, particularly negative emotions, may trigger a defensive shifting of attention: To protect oneself from the unpleasant impact of an event, one may deliberately focus on unimportant trivia at the event's fringe (see Larsen \& Plunkett, 1985). This concept is consistent with the fact that vivid memories are often filled with recalled minutiae (the clothing worn by the participants in the event, attendant sights and smells, etc.). A second possibility is that emotion's effects may simply result from arousal per se, perhaps because arousal generally enhances encoding (Clark, Milberg, \& Ross, 1983; Kleinsmith \& Kaplan, 1964), or perhaps because sufficiently high levels of arousal trigger some specialized encoding mechanism. This last possibility was specifically suggested by Brown and Kulik (1977), drawing on a biological mechanism described by Livingston (1967).

These two possibilities differ on many points, including their predictions about the role of affective valence. Surprisingly, little evidence exists concerning the role of affective valence in creating memory vividness. Hence, in our first experiment, we collected responses to a questionnaire, which asked subjects to rate 16 events on a variety of measures. The rating scales of greatest interest 
asked subjects how vivid their recollections of the events were, and how emotional the events had been, on a signed scale ranging from made me very sad to made me very happy. Our second experiment replicated the first, but required finer distinctions among emotions. Our third experiment utilized an interview procedure, intended primarily as a validation of the questionnaire procedures. Our questionnaires required subjects to perform a magnitude estimation of vividness; the interview asked whether these numerical judgments corresponded meaningfully to the richness and completeness of recollection. In all three experiments, other scales provided subsidiary information, as discussed below.

\section{EXPERIMENT 1}

\section{Method}

Twenty-four questionnaires were completed and analyzed in the first study. These listed 16 events chosen to span the range of positive and negative affect (e.g., "unexpected death of a close friend or relative," "passing some major examination in school"). Each subject rated each event for (1) how vivid the memory was, (2) what the emotional reaction to the event was, (3) how surprising the event was, (4) how consequential the event was in the respondent's life, and (5) how often the subject used the event as a reference point in temporally locating other events in memory. Subjects were given a 1-7 rating scale for each of these dimensions (except for the affect dimension, for which the scale ranged from -7 to +7$)$.

For each scale, the subjects were instructed to rate as best they could how they reacted to the event at the time it happened. On all scales, there was also a "does not apply" response available, and the subjects were urged to distinguish (for example) "zero"' vividness, for events experienced and not remembered, from events never experienced. Instructions for each scale described the dimension being assessed. The instructions for vividness asked the subject how "complete and detailed" the memory was. The instructions for consequentiality followed the definition offered by Brown and Kulik (1977), and explicitly asked the subject not to judge how "historically prominent" the event was, but whether the event "changed [his/her] life."

The respondents were all students or faculty at the New School for Social Research. The respondents ranged in age from 24 to 76 , with a mean of 39 . Ten subjects were male, 13 female; 1 subject omitted this information.

\section{Results}

Ratings were first analyzed separately for each subject, by computing correlations across the various events. To determine the pattern across subjects, each subject's $r$ was then converted via the Fisher transformation to a $Z$ score, and then all analyses were performed on these $Z$ scores. All correlations reported here are the back-transform of the mean $Z$; probability values reported reflect the consistency of the Zs across subjects.

There was no correlation between vividness and signed affect, that is, ratings of the events from -7 (very sad) to +7 (very happy) $(r=.009)$. In contrast, the relation between vividness and strength of affect (unsigned) was quite robust $(r=.554, p<.001)$. There was in fact a $\mathrm{V}$-shaped relation between signed affect and vividness, with vivid memories associated with departures from zero affect in either the sad or happy direction. This symmetry is clear if we look separately at the correlation between vividness and affect for emotionally positive events and at that between vividness and affect for emotionally negative events ( $r=.481$ and -.567 , respectively).

There was no relation between memory vividness and the degree of surprise associated with an event $(r=$ -.110, n.s.). Vividness was associated with the judgment that the remembered event changed one's life $(r=.647$, $p<.001)$ and with frequent use of an event as a temporal reference point $(r=.644, p<.001)$. The judgments of the event's consequentiality and of use of the event as a reference point are themselves closely linked $(r=.830, p<.001)$.

\section{EXPERIMENT 2}

\section{Method}

Our second study closely followed the format of the first, with the following changes: The subjects made separate assessments of the strength of the emotion associated with an event and of the character of the emotion. For the strength ratings, a 1-7 scale was provided; the subjects then indicated whether the event had made them happy, sad, angry, afraid, or "other."

The subjects were also asked to assess what it was about an event that they remembered: the content of the event itself or their own personal experience of the event (hearing the news, thinking about it subsequently, etc.). The subjects rated their memories on a scale ranging from entirely the experience of the event to balanced both to entirely the event itself. The experience was defined in the instructions as "how things looked to you, how things sounded, what you thought about"; the event was defined as "what happened, who was involved, independent of your personal experience of it." These definitions were followed by two examples, the Kennedy assassination and the Jonestown disaster.

The instructions for the vividness scale were modified to emphasize that the subjects should not rate a memory as vivid if they clearly remembered only one or two salient details, including remembering only that they had been very sad or the like. This was intended to minimize the chance that subjects might automatically rate as vivid any event for which they remembered strong emotion.

This study used a larger event set (48 events) to support the analyses of the more refined affect categories. Questionnaires were returned by 20 subjects, recruited from introductory lecture courses at the New School for Social Research. The subjects ranged in age from 22 to 34 .

\section{Results}

As before, results were computed for individual subjects and then pooled across subjects. Judgments of memory vividness were highly correlated with both strength of affect (pooling across categories, $r=.705$ ) and the judged consequentiality of the event $(r=.514)$. With increasing affect, the subjects were more likely to remember their own experiences, rather than the outward event itself $(r=-.335$; the negative correlation reflects an arbitrary assignment of low numbers to the experience end of the scale). Likewise, increasing consequentiality enhanced the likelihood that it was the experience that was remembered $(r=-.216)$.

The correlations beween affect strength and vividness were quite consistent across different affects: for happy events, $r=.714$; for sad events, .889 ; for angry events, .685 ; for fearful events, .900 . Likewise, the relation between vividness and consequentiality was also consistent across these categories $(r=.500, .661, .612, .772$, respectively). The association between emotionality and memories' being dominated by the experience itself also 
held across affect categories, with the correlation between affect and this measure narrowly ranging from -.238 (for happy events) to -.370 (for angry events).

The ratings were analyzed separately for personal events (e.g., death of a parent, graduation from college) and for public events (e.g., first moon landing). Personal events were more vividly remembered and more emotional than public events $[5.38$ vs. $3.57, t(19)=7.76, p<.002$, and 5.30 vs. $3.47, t(19)=5.95, p<.002$, respectively], but the relations between vividness and affect strength were the same for personal and public events $(r=.661$ and .641 , respectively). The correlations between vividness and consequentiality were .421 and .515 for personal and public events; the correlations between affect strength and the content assessment were -.244 and -.361 .

In sum, these statistical relations are remarkably robust across both different categories of affect (negative and positive, in our first study; four individual affects in our second) and different categories of event (personal vs. public). However, many researchers have questioned the accuracy of subjects' self-assessments of their memories (Harris \& Morris, 1986; Hermann, 1982; Sunderland, Harris, \& Gleave, 1984), we therefore cannot presume the veracity of subjects' vividness judgments without further validation.

\section{EXPERIMENT 3}

\section{Method}

Six subjects were recruited for our final study. They first filled out the questionnaire of the second study, and then were interviewed to determine how much they actually remembered about 16 of the 48 events on the questionnaire, a subset chosen to span personal and public events, and both events rated affectively positive and negative. The subjects were first asked to provide as full a recounting of each event as possible. At the end of this spontaneous report, the interviewer asked a preset series of probe questions. These were all of the form "You did not mention ...; Do you remember ...?"' The list of probes included the weather, attire, what people were present, the date and time, and the subject's mood and thoughts at the time. There were also some open-ended questions, including "Was there anything that struck you as special about the event?"

The interviews (which required 5-7 h per subject) were recorded and transcribed. The subjects ranged from 22 to 33 in age $(M=27) ; 3$ were male, and 3 female.

This procedure, of course, contains a strong demand component: A subject who had claimed a vivid memory in the numerical rating may strive to remember more, to justify that rating. To minimize this possible effect, the subjects were told at the outset that they might discover, when recounting their memories, that they remembered more or less than they initially judged. The subjects were told that, in this case, they were free to modify their original vividness rating. Additionally, the subjects were explicitly asked, after the questions for each event, if they wished to modify their original judgment. (Overall, the subjects took either of these options to modify a rating in only $9 \%$ of the events.) Finally, the interviewer (who was blind to what vividness rating the subject had assigned) maintained a consistent level of probing, employing only the predetermined probe questions.

\section{Results}

Judges analyzed the transcripts for three categories of material: reports of plot, reports of setting, and reports of remembered judgments or emotions. These categories were chosen largely for their ease of coding, given the simple question we were seeking to ask about the degree of detailedness of these memory records. As part of our further exploration of these recall protocols, a muchrefined analysis scheme is being developed. Two independent judges did the scoring; they agreed in $92 \%$ of the cases in deciding whether an element was in fact an element, in $82 \%$ of the cases in categorizing the element. All disagreements were decided by a third judge.

The richness of the subjects' reports corresponded well with their estimates of vividness. The subjects' ratings of vividness were significantly correlated with the number of plot details reported $(r=.524, p<.001)$, the number of setting details $(r=.590, p<.005)$, and the number of details of remembered thoughts and feelings $(r=.536, p<.001)$. The correlation between affect strength and vividness was also replicated $(r=.474)$. (This correlation is notably lower than the corresponding correlation in the prior studies. We presume this to be an artifact of the small $N$ in the third study.)

\section{GENERAL DISCUSSION}

Vivid memories are reliably associated with strong emotion, but the species of the emotion is irrelevant to the creation of vividness. Instead, it is emotional arousal per se that is critical in creating vivid memories. Moreover, the correlations indicate a linear relation between degree of arousal and degree of vividness; a similar relation holds between the degree of arousal and the degree to which one's immediate experience of an event dominates the memory.

These results speak against a simple view of how emotion might shape memory, namely, what Hollingworth (1910) called an "obliviscence of the disagreeable" in autobiographical recall. (For reviews of this early literature, see Dudycha \& Dudycha, 1941; Matlin \& Stang, 1978; Waldfogel, 1948.) This conception of memory implies that positive affect will lead to richer and fuller memories than negative affect; this is, of course, contradicted by our data. (This claim is also inconsistent with the fact that many of the well-studied, very vivid flashbulb memories concern deaths and assassinations.)

If it is arousal per se that creates memory vividness, what is the mechanism? One possibility is that the fact of remembered arousal itself spurs the subject to greater efforts at recall or reconstruction of the original event. In Bartlett's (1932) terms, a subject remembers the affect itself and so strives to "justify the attitude." This kind of view implies that some of the reconstructed details may not be true to fact. One might alternatively claim that arousal directly facilitates the memory encoding process, perhaps by augmenting the processing resources available (Eysenck, 1982; Kahneman, 1973) or perhaps by directly facilitating memory entry (Gold, 1987). Either of these latter possibilities predicts that arousal will produce accurate and detailed memories.

One frequently cited claim appears to favor the former, reconstructive, view. According to Easterbrook's (1959) hypothesis, increasing levels of arousal lead to a narrow- 
ing of attention. (See Eysenck, 1982, for a recent review of Easterbrook's claim.) Hence, subjects aroused by an experienced event may have more attention to devote to the informational core of this event, but are unlikely to note details and appearances at the event's periphery. In this case, vivid memories for emotional events would not be populated with remembered details, as these were never encoded. Instead, the details of vivid memories are presumably reconstructed (cf. Bruner, 1986; Bruner, Matter, \& Papanek, 1955; Loftus, 1982; Neisser, 1982).

We should be cautious about this claim, however, since the evidence for Easterbrook's hypothesis typically involves on-line use of available cues. Although these studies do show diminished use of peripheral cues at the time the arousal is actually on the scene, this does not imply that long-term retention of these cues will be likewise impaired. Several studies have shown disruptive effects of arousal on tests of short-term memory but facilitative effects on long-term retention (Christianson, 1984; Kleinsmith \& Kaplan, 1964). These findings clearly urge skepticism about extrapolating from the Easterbrook laboratory data to cases of very-long-term autobiographical recall.

Heuer (1988) presented evidence that, in a laboratory setting, emotional arousal does promote accurate retention (after a 2-week interval) of both information central to an event and of minutiae that accompanied the event. These data are (as far as we know) the only laboratory data that speak directly to the kinds of remembered details that fill our interview subjects' protocols. (Christianson and Loftus, in press, also reported on long-term retention of peripheral detail, but detail of a seemingly different sort.) The veracity of subjects' recall in Heuer's procedure clearly speaks to arousal's mechanisms: We read these data as favoring the suggestion that arousal serves to facilitate encoding of a broad spectrum of information, and hence leads to the creation of accurate vivid memories.

\section{REFERENCES}

Baddeley, A. (1982a). Amnesia: A minimal model and an interpretation. In L. Cermak (Ed.), Human memory and amnesia. Hillsdale, NJ: Erlbaum.

Baddeley, A. (1982b). Domains of recollection. Psychological Review, 89, 708-732.

Bartlett, F. (1932). Remembering. New York: Cambridge University Press.

Brown, R., \& Kulik, J. (1977). Flashbulb memories. Cognition, 5, 73-99.

Bruner, J. (1986). Actual minds, possible worlds. Cambridge, MA: Harvard University Press.

Bruner, J., Matter, J., \& Papanek, M. (1955). Breadth of learning as a function of drive level and mechanization. Psychological Review, 42, 1-10.
Christianson, S.-A. (1984). The relationship between induced emotional arousal and amnesia. Scandinavian Journal of Psychology, 25, 147-160.

Christianson, S.-A., \& Loftus, E. (in press). Memory for traumatic events. Applied Cognitive Psychology.

Clark, M., Milberg, S., \& Ross, J. (1983). Arousal cues arousalrelated material in memory: Implicatons for understanding effects of mood on memory. Journal of Verbal Learning \& Verbal Behavior, 22, 633-649.

Dudycha, G., \& Dudycha, M. (1941). Childhood memories: A review of the literature. Psychological Bulletin, 38, 668-682.

EASTERBRooK, J. (1959). The effect of emotion on cue utilization and the organization of behavior. Psychological Review, 66, 183-201.

EYSENCK, M. (1982). Attention and arousal: Cognition and performance. Berlin: Springer-Verlag.

Gold, P. (1987). Sweet memories. American Scientist, 75, 151-155.

HARRIS, J., \& Morris, P. (1986). Everyday memory, action and absentmindedness. New York: Cambridge University Press.

HermanN, D. (1982). Know thy memory: The use of questionnaires to assess and study memory. Psychological Bulletin, 92, 434-452.

Heuer, F. (1988). Remembering detail: The role of emotion in longterm memory. Manuscript submitted for publication.

HollingwORTH, H. (1910). The obliviscence of the disagreeable. Journal of Philosophical \& Psychological Science Methods, 7, 709-714.

JACOBY, L. (1982). Knowing and remembering: Some parallels in the behavior of Korsakoff patients and normals. In L. Cermak (Ed.), $\mathrm{Hu}$ man memory and amnesia. Hillsdale, NJ: Erlbaum.

Johnson, M. (1985). The origin of memories. Advances in CognitiveBehavior Research \& Therapy, 4, 1-27.

Kahneman, D. (1973). Attention and effort. Englewood Cliffs, NJ: Prentice Hall.

Kleinsmith, L., \& Kaplan, S. (1963). Paired associate learning as a function of arousal and interpolated interval. Journal of Experimental Psychology, 65, 190-193.

Larsen, S., \& Plunkett, K. (1985). Remembering personal and reported events. Applied Cognitive Psychology, 1, 15-26.

LivingSTON, R. (1967). Brain circuitry relating to complex behavior. In G. Quarton, T. Melnechuck, \& F. Schmitt (Eds.), The neurosciences: A study program. New York: Rockefeller University Press.

LofTus, E. (1982). Remembering recent experiences. In L. Cermak (Ed.), Human memory and amnesia (pp. 239-256). Hillsdale, NJ: Erlbaum.

Matlin, M., \& Stang, D. (1978). The Pollyanna principle: Selectivity in language, memory, and thought. Cambridge, MA: Schenckman.

NeISSER, U. (1982). Snapshots or benchmarks? In U. Neisser (Ed.), Memory observed (pp. 43-48). San Francisco: W. H. Freeman.

Pillemer, D. (1984). Flashbulb memories of the assassination attempt on President Reagan. Cognition, 16, 63-80.

Rubin, D., \& Kozin, M. (1984). Vivid memories. Cognition, 16, 81-95. SChacter, D., \& Tulving, E. (1982). Memory, amnesia and the episodic/semantic distinction. In R. Isaacson \& N. Spear (Eds.), Expression of knowledge. New York: Plenum Press.

Sunderland, A., Harris, J., \& Gleave, J. (1984). Memory failures in everyday life following servere head injury. Journal of Clinical Neuropsychology, 6, 127-142.

WALDFOGEL, S. (1948). The frequency and affective character of childhood memories. Psychological Monographs, 62.

WinOGRAD, E., \& KiLLINGER, W. (1983). Relating age at encoding in early childhood to adult recall: Development of flashbulb memories. Journal of Experimental Psychology: General, 112, 413-422.

(Manuscript received for publication August 4, 1987.) 